\title{
Issues surrounding end-of-life decision-making
}

\author{
This article was published in the following Dove Press journal: \\ Patient Preference and Adherence \\ 8 August 2013 \\ Number of times this article has been viewed
}

\section{Vickram Tejwani ${ }^{1, *}$ \\ YiFan Wu ${ }^{1, *}$ \\ Sabrina Serrano ${ }^{2}$ \\ Luis Segura ${ }^{2}$ \\ Michael Bannon ${ }^{3}$ \\ Qi Qian'}

'Department of Medicine, Division of Nephrology and Hypertension, ${ }^{2}$ Mayo Graduate School, ${ }^{3}$ Department of Trauma, Critical Care, and General Surgery, Mayo Clinic College of Medicine, Rochester, MN, USA

*These authors contributed equally to this work
Correspondence: Qi Qian

Department of Nephrology and Hypertension, Mayo Clinic, 200 First Street SW, Rochester, MN 55905, USA

Tel + I 5072667960

Fax + I 507266789 |

Email qian.qi@mayo.edu
Abstract: End-of-life decision-making is a complex process that can be extremely challenging. We describe a 42-year-old woman in an irreversible coma without an advance directive. The case serves to illustrate the complications that can occur in end-of-life decision-making and challenges in resolving difficult futility disputes. We review the role of advance directives in planning end-of-life care, the responsibility and historical performance of patient surrogates, the genesis of futility disputes, and approaches to resolving disputes.

Keywords: end-of-life care, advance directive, surrogate, futility dispute, conflict resolution

\section{Case vignette}

A 42-year-old female was admitted to the intensive care unit for an acute, massive subdural hematoma complicated by brainstem herniation following an accidental fall. She had been on hemodialysis for 10 years for renal failure due to diabetic nephropathy. She had multiple thrombotic occlusions of large vessels associated with dialysis catheters and was placed on long-term anticoagulation (warfarin) therapy. She was denied for kidney transplant due to medication compliance issues.

Upon admission, she underwent emergent evacuation of the hematoma. Although the operation went well, postoperatively she was ventilator-dependent and in a persistent coma. She subsequently developed multiorgan failure and her dialysis catheter became nonfunctional. After repeated attempts to restore line patency, the interventional radiologists concluded that her vessels were so diseased that further attempts would unlikely be successful. Her neurologists, meanwhile, concluded that her brain was so damaged that she would not recover consciousness. She unfortunately had no advance directive to guide end-of-life decision-making. Her husband, her surrogate decision-maker, requested everything possible continue to be done, including invasive interventions to sustain life. The care team felt invasive measures would not be in her best interest, as further interventions could inflict trauma and would not change her outcome. A futility dispute ensued. After extensive face-to-face communications between the care team and the patient's family, and multiple care conferences with involvement of the institutional ethics committee, the patient's surrogate and family had a better understanding of the nature of the patient's condition and the limitations of modern interventional/life-sustaining devices. Ultimately, consensus was reached on providing comfort care for the patient. Here, we review key issues surrounding end-of-life decision making with emphasis on the role of advance directives and surrogates in the process and approaches to resolving futility disputes. 


\section{Advance directive}

An advance directive is a set of instructions recognized under state law in reference to the provision of health care when the individual is incapacitated. ${ }^{1}$ It communicates one's wishes to family, friends, and health care professionals in the event of becoming unable to voice one's own wishes. Ideally, upon completion of an advance directive, the individual should review the contents with his/her care provider to clarify his/ her general wishes. Advance directives may also include durable powers of attorney, a document designating a surrogate decision-maker if the individual is incapacitated. Although typically written, verbal advance directives are valid in most states. ${ }^{2}$

In 1990, Congress passed the Patient Self-Determination Act to promote patients' rights for making decisions regarding their medical care even when decisional capacity is lost. Under this law, Medicare and Medicaid providers are required to inform all patients of their right to accept or refuse medical interventions, their rights regarding advance directives, and institutional policies addressing the withholding and/or withdrawal of life support. ${ }^{3}$

The key role for an advance directive in end-of-life care is demonstrated in a study by Silveira et $\mathrm{al}^{4}$ showing that patients with advance directives are much more likely to receive end-of-life care consistent with their preferences; $83.2 \%$ of patients who requested limited care received it and $97.1 \%$ who requested comfort care received it. Those patients died in hospitals (38.9\%), homes $(27.3 \%)$, or nursing homes $(24.5 \%)$. Other studies also show a reduction in resource utilization in patients with advance directives. ${ }^{5,6}$ The lower resource utilization, including less use of life-sustaining treatment, greater use of hospice care, and less likelihood of terminal hospitalization, did not seem to affect the perceived quality of end-of-life care. ${ }^{5,6}$ Thus, the growing consensus is that every adult, regardless of age, should consider preparing an advance directive because unforeseeable accidents can and do occur, as in this case.

Despite advance directives being advocated, a majority of the population in the United States do not have advance directives. In fact, an American Association of Retired Persons poll in 2008 found that despite $92 \%$ of adults having heard of living wills, only $36 \%$ actually completed one. ${ }^{7}$ Although the usage of advance directives increases with age, the rate of completing advance directives paradoxically decreases with declining health status. ${ }^{6}$ This paradox might involve denial, fear of obtaining less than maximal medical attention if endof-life care preferences are declared as nonaggressive, or considering the designation of a surrogate as sufficient. ${ }^{8}$
In our case, the patient did not have an advance directive, and the care team looked to her surrogate, her husband, for establishing goals of care. In reality, however, all family members were intimately involved in the decision process and collectively functioned as the surrogate.

\section{The surrogate}

A surrogate, also termed a proxy, is a person designated by the durable powers of attorney, who speaks for the patient. ${ }^{1,9}$ If there is no predesignated surrogate, the patient's legal guardian will automatically assume the role. In the absence of a legal guardian, a spouse, by default, becomes the surrogate, followed by an adult son or daughter, either parent, an adult sibling, an adult grandchild, a close friend and, lastly, the guardian of the estate if none of the former is available. ${ }^{9}$ The specific sequence may vary by state.

The surrogate's responsibility is to implement the patient's advance directive when available. In the absence of an advance directive, the surrogate should implement the patient's known preferences. If the patient's preferences are unknown, the surrogate should advocate for the patient's welfare and make decisions in the best interest of the patient. ${ }^{10}$ Having an advance directive does not automatically mean that the patient declines aggressive intervention. Some individuals may prefer not to state their explicit wishes and thus may grant the surrogate a higher level of authority. In other cases, individuals may have very specific instructions for the surrogate, stating specifically what needs to be done when the time comes, including how end-of-life decisions might be made, what other individual(s) may be involved to help the surrogate with decision-making, and what specific values and preferences the surrogate is expected to follow. ${ }^{1}$ Regardless of the level of authority granted, an ideal surrogate should always participate in collaborative decision-making with the care providers. If a surrogate avoids communication or requests interventions that are clearly not considered in the patient's best interest, counseling should be provided. If counseling is unsuccessful, replacement of the surrogate should be considered.

Ideally a surrogate makes a decision for a patient on the basis of substituted judgment. That is, the surrogate makes the decision he/she feels the patient would make. In order to exercise substituted judgment, the surrogate must have a good understanding of the patient's values and medical preferences. It is critically important that the patient and surrogate discuss the key issues before the patient loses decisional capacity. It need not take place in conjunction with completion of the advance directive but must, nevertheless, 
be held. Difficulty arises when end-of-life decisions must be made when the surrogate has not had previous clear conversation with patient. The surrogate must then try to distill their perhaps limited knowledge of the patient's values into a decision under intensely stressful circumstances. Historically, surrogate performance has been less than optimal in these cases. Hines et al interviewed 42 patientsurrogate pairs and found that surrogates often lack the information needed to serve as a surrogate decision-maker, mainly due to their failure to obtain the patient's specific views on end-of-life values and preferences. ${ }^{11}$ A systematic review by Shalowitz et al also indicated that surrogates predict treatment desired by patients with only $68 \%$ accuracy. ${ }^{12}$ Emotional closeness, stress, and religious beliefs are some of the reasons for deviating from representing the patient's true desires. In the era of heavy social media, surrogates are not immune to unfounded and sensational anecdotes, which may give surrogates unrealistic hope with regard to therapies and recovery. Surrogates may occasionally have tenets that involve the expectation of a miracle. Clearly outlined and frequently updated advance directives, discussed with family and surrogates, can minimize these pitfalls. Without such information, the surrogate is left to make a decision by the best interest standard, ie, the surrogate must make a decision based upon what the surrogate believes is best for the patient. As described below, the lack of advance directives can be a source of futility disputes.

In our case, the family indicated that they had no prior discussion with the patient regarding end-of-life care. Given the patient's loss of mental capacity and multiorgan failure, the care team considered comfort care to be justified. However, the patient's family rejected the recommendation and expressed a strong feeling that a miracle would occur and the patient would regain consciousness and recover. Based on this hope, they requested continuation of unlimited lifesustaining measures, including dialysis, vasopressor drips, mechanical ventilation, and resuscitation for cardiac arrest. Despite being repeatedly informed that these measures would not alter the patient's outcome, the family persisted in their requests. The care team felt the family's expectations to be unrealistic and their demands unreasonable. Opposing beliefs regarding the patient's prognosis and goals of care resulted in a futility dispute.

\section{Futility disputes}

A futility dispute occurs when physicians and the patient's family or surrogate have opposite views on what kind of care is appropriate for the patient; typically, the physicians consider aggressive care to be futile and comfort care appropriate, while the patient's family or surrogate disagree. ${ }^{9}$ Futility disputes touch upon multiple aspect of care-related issues. They involve moral judgments on what constitutes ethical care, the obligation to preserve both the patient's and physician's autonomy, and distinguishing an effect in an organ from an actual improvement in patient outcome.

Prior to the intensive care era, patients succumbed to organ failure without organ replacement therapy. ${ }^{13}$ There was no burden on physicians or families to choose the type of terminal care modality. With the advent of the medical intensive care units and modern technology, prolonging life by artificial life support devices became possible. The existence of mechanical ventilation for respiratory failure, dialysis for renal failure, and intra-aortic balloon pump and artificial heart for end-stage heart failure and more, fosters a growing perception that modern medicine is capable of exerting control over life and death. However, in many cases, artificial life support serves only to prolong the patient's dying process without providing any overall benefits, especially for those with permanent loss of mental capacity and multiorgan failure. After an initial period of overzealous use of organ replacement support, physicians have recognized their limitations. A study by Prendergast and Luce showed that the rate of withholding or withdrawing life support almost doubled from the period of 1987-1988 to 1992-1993 $(51 \%$ to $90 \%){ }^{14}$

In the Internet era, the general public is well versed on the crisis in health care financing and reimbursement. Physician recommendations to limit or withdraw medical interventions near the end-of-life may be perceived as being motivated by cost containment, which can erode trust between physicians and the general public. This phenomenon may be exacerbated by the fact that the acute care physicians typically have no prior relationship with the patient, communication between physicians and patients' family on end-of-life care is often inadequate, ${ }^{15}$ and there is continued controversy regarding what constitutes futility, ${ }^{8}$ despite attempts to define it. ${ }^{16}$ Not surprisingly, recent studies show that two thirds of surrogate decision-makers would not believe a doctor if informed that treatment was futile, ${ }^{17}$ and nearly $75 \%$ of the public believe that they have the right to demand care not recommended by physicians. ${ }^{9}$ Taken together, diminished trust in physician judgment and failure to recognize limitations of modern life support systems by the public set the stage for futility disputes. In our case, due to the differences in the view of the patient's outcome, the dispute reached an impasse that had to be resolved. 


\section{Resolving futility disputes}

The consequences of unresolved or suboptimally resolved futility disputes are multiple. First, they generate or perpetuate dissatisfaction among the patient's surrogate and family in the medical care provided, as the clinical condition in terminally ill patients tends to deteriorate over time. Second, providing invasive care to a corporeal being with no hope of recovery creates emotional and moral distress in care providers, as active interventions may violate the patient's autonomy and providers may consider themselves agents of harm. ${ }^{9}$ Lastly, continuation of intensive care for permanently unconscious and terminally ill patients potentially diverts health care resources from patients with reversible illnesses. ${ }^{18-21}$

Although several approaches have been applied, futility disputes are, in general, best resolved through surrogate-care provider collaboration. ${ }^{9}$ Unilateral decision-making by the surrogate or physician is much less optimal. Blindly following the surrogate's wishes is not always in the patient's best interest and most surrogates tend to request "do everything possible". Although in some circumstances, this achieves nothing more than inflicting bodily injury on the patient, it should be ensured the request is further clarified and the rationale appropriately explored. ${ }^{22}$ Patient care providers, on the other hand, tend to recommend comfort care for patients without a prospect of regaining consciousness and those who are terminally ill. ${ }^{23}$ Disregarding the surrogate's requests can lead to dissatisfaction and potential legal issues. In the United States, Texas is the only state where health care providers are granted power to refuse patient-requested or surrogaterequested treatment that the provider deems inappropriate. Although unilateral decisions by doctors and hospital committees are permitted, the Texas law is being applied only as a last resort. ${ }^{24}$ Early experience showed that decisions rendered under the law were in favor of the surrogates' views in fewer than $10 \%$ of cases. ${ }^{25}$ Whether the law ensures fair deliberation needs to be more rigorously examined. Other care facilities, without a law similar to that in Texas, turn to the courts to resolve futility disputes. Unfortunately, this route often proves wanting. For example, in August 2010, the Superior Court of New Jersey declined to rule in an end-of-life care case, citing lack of benefit in judicial intervention in such medically complicated disputes. ${ }^{26}$ Therefore, every effort should be made to resolve a futility dispute in a surrogateprovider collaborative manner, which has been the strategy utilized in the majority of disputes. ${ }^{9}$

A resolution born out of surrogate-provider collaboration can be time-consuming and require a stepwise strategy and coordinated team approach. Agreement rate is low at the initial discussion, but increases with repeated interactions. Siegel has proposed a useful outline on how to approach surrogates and family members, emphasizing the importance of frequent meetings, thoroughly answering questions and concerns, and tailoring approaches to individual family situations. ${ }^{27}$ Patients who have strong religious beliefs underlying their rationale will benefit from acknowledgment of their beliefs. ${ }^{28}$ Multiple institutional resources should be utilized to facilitate communication and mutual understanding. Social workers can help with understanding the disease process and facilitate care delivery. ${ }^{25}$ The ethics committee interacts with both the patient's family and physicians to ensure a fair process in which the patient's rights are respected and their welfare is protected. ${ }^{27}$ Palliative care service can also be consulted and can help with establishing the goals of care. These strategies can improve the probability of reaching adequate goals of care in a mutually understanding manner.

In this case, a social worker had been actively working with the patient's family. The team also involved the ethics committee, which worked closely with all parties to promote communication and shared decision-making. Another care conference was convened which included the multidisciplinary care team, the patient's family (the surrogate husband, her parents, three sisters, two brothers, and two cousins), an ethics committee representative, nurses, a social worker, and a chaplain. The medical team reiterated the grim prognosis and proposed comfort care for the patient. The patient's family initially persisted in continuing all interventions on grounds that "God will cure her all the way". The conference was initially hostile and emotionally intense. Some family members accused the physicians of never having experienced their circumstance, not believing in the "powers of God", and of giving up. The medical team persisted in its view, emphasizing the irreversible nature of her condition, respect for her dignity, and avoiding further harm at near end-of-life. The care team responded to all of the family's questions with detailed and thorough explanations in an empathic and emotionally supportive manner. The nearly two-hour meeting concluded with the family's consensus on do-not-resuscitate and no further invasive procedure for dialysis line placement. The family was not ready for comfort care and the providers respected their wishes.

Following the conference, palliative service was consulted. The palliative care team continued daily dialog with the patient's family and provided updates on the patient's condition. Ultimately, consensus was reached for providing comfort care to our patient. She was extubated and expired peacefully. 


\section{Comments}

This case illustrates the complications that can occur without an advance directive and the challenges of resolving difficult futility disputes. Nearly half of patients lose decision-making capacity near the end of their life and over two thirds of this half face choices on specific end-of-life treatment options. The choices are often made by the patient's surrogate and family, with whom the care providers must work closely to deliver end-of-life care. Given the negative clinical, ethical, and legal implications of unresolved futility disputes, it is important for clinicians to be knowledgeable about the utility of advance directives, the role and responsibility of designated surrogates, and options and institutional resources that can be utilized to facilitate conflict resolution. Better communication and understanding of the capacity and limitations of life-sustaining devices can ameliorate dissatisfaction and facilitate delivery of end-of-life care best representing the patient's preferences.

\section{Disclosure}

The authors report no conflicts of interest in this work.

\section{References}

1. Emanuel LL. Advance directives. Annu Rev Med. 2008;59:187-198.

2. Castillo LS, Williams BA, Hooper SM, Sabatino CP, Weithorn LA, Sudore RL. Lost in translation: the unintended consequences of advance directive law on clinical care. Ann Intern Med. 2011;154:121-128.

3. Congress s. Patient Self Determination Act of 1990. In: Congress s, ed. Vol H.R. 44491990.

4. Silveira MJ, Kim SY, Langa KM. Advance directives and outcomes of surrogate decision making before death. $N$ Engl J Med. 2010;362: 1211-1218.

5. Molloy DW, Guyatt GH, Russo R, et al. Systematic implementation of an advance directive program in nursing homes: a randomized controlled trial. JAMA. 2000;283:1437-1444.

6. Teno JM, Gruneir A, Schwartz Z, Nanda A, Wetle T. Association between advance directives and quality of end-of-life care: a national study. $\mathrm{J} \mathrm{Am}$ Geriatr Soc. 2007;55:189-194.

7. Nelson DV. AARP Bulletin Poll "Getting Ready to Go" Executive Summary. 2008. Available from: http://assets.aarp.org/rgcenter/i1/ getting_ready.pdf. Accessed May 9, 2013.

8. Smith DH, McKhann C, Peppard C, Duffy D, Rosenbaum S, editors What's the Point? Clinical Reflections on Care That Seems Futile. 2005. Available from: http://www.yale.edu/bioethics/publications/Medical Futility.pdf. Accessed May 9, 2013.
9. Pope TM. Surrogate selection: an increasingly viable, but limited, solution to intractable futility disputes. Saint Louis University Journal of Health Law and Policy. 2010;3:183-252.

10. Emanuel EJ, Emanuel LL. Proxy decision making for incompetent patients. An ethical and empirical analysis. JAMA. 1992;267: 2067-2071.

11. Hines SC, Glover JJ, Babrow AS, Holley JL, Badzek LA, Moss AH. Improving advance care planning by accommodating family preferences. J Palliat Med. 2001;4:481-489.

12. Shalowitz DI, Garrett-Mayer E, Wendler D. The accuracy of surrogate decision makers: a systematic review. Arch Intern Med. 2006;166: 493-497.

13. Puri N, Puri V, Dellinger RP. History of technology in the intensive care unit. Crit Care Clin. 2009;25:185-200, ix.

14. Prendergast TJ, Luce JM. Increasing incidence of withholding and withdrawal of life support from the critically ill. Am J Respir Crit Care Med. 1997;155:15-20.

15. White DB, Engelberg RA, Wenrich MD, Lo B, Curtis JR. Prognostication during physician-family discussions about limiting life support in intensive care units. Crit Care Med. 2007;35:442-448.

16. Schneiderman LJ, Jecker NS, Jonsen AR. Medical futility: its meaning and ethical implications. Ann Intern Med. 1990;112:949-954.

17. Zier LS, Burack JH, Micco G, Chipman AK, Frank JA, White DB. Surrogate decision makers' responses to physicians' predictions of medical futility. Chest. 2009;136:110-117.

18. Skowronski GA. Bed rationing and allocation in the intensive care unit. Curr Opin Crit Care. 2001;7:480-484.

19. Oye RK, Bellamy PE. Patterns of resource consumption in medical intensive care. Chest. 1991;99:685-689.

20. Sulmasy DP, Bloche MG, Mitchell JM, Hadley J. Physicians' ethical beliefs about cost-control arrangements. Arch Intern Med. 2000;160: 649-657.

21. Niederman MS, Berger JT. The delivery of futile care is harmful to other patients. Crit Care Med. 2010;38(Suppl 10):S518-S522.

22. Quill TE, Arnold R, Back AL. Discussing treatment preferences with patients who want "everything". Ann Intern Med. 2009;151:345-349.

23. Verhagen AA, de Vos M, Dorscheidt JH, Engels B, Hubben JH, Sauer PJ. Conflicts about end-of-life decisions in NICUs in The Netherlands. Pediatrics. 2009;124:e112-119.

24. Hospital P. Guidelines for Treatment and Life-Support Decision Making. Administrative Procedure Manual. 2013. Available from: http://parklandhospital.com/patients_visitors/pdf/lifesupportadult.pdf. Accessed June 19, 2013

25. Fine RL, Mayo TW. Resolution of futility by due process: early experience with the Texas Advance Directives Act. Ann Intern Med. 2003;138:743-746.

26. White DB, Pope TM. The courts, futility, and the ends of medicine. JAMA. 2012;307:151-152.

27. Siegel MD. End-of-life decision making in the ICU. Clin Chest Med. 2009;30:181-194, x.

28. Balboni TA, Paulk ME, Balboni MJ, et al. Provision of spiritual care to patients with advanced cancer: associations with medical care and quality of life near death. J Clin Oncol. 2010;28:445-452.
Patient Preference and Adherence

\section{Publish your work in this journal}

Patient Preference and Adherence is an international, peer-reviewed, open access journal focusing on the growing importance of patient preference and adherence throughout the therapeutic continuum. Patient satisfaction, acceptability, quality of life, compliance, persistence and their role in developing new therapeutic modalities and compounds to

\section{Dovepress}

optimize clinical outcomes for existing disease states are major areas of interest. This journal has been accepted for indexing on PubMed Central. The manuscript management system is completely online and includes a very quick and fair peer-review system. Visit http://www.dovepress.com/ testimonials.php to read real quotes from published authors. 